\title{
Plantas bioativas para uso \\ no paisagismo
}

REVISTA ELETRÔNICA CIENTÍFICA DA UERGS

Janine Farias Menegaes

Universidade Federal de Santa Maria (UFSM).

E-mail: janine_rs@hotmail.com, https://lattes.cnpq.br/632058I8203287/8

Fernanda Alice Antonello Londero Backes

Universidade Federal de Santa Maria (UFSM).

E-mail: prof.fernanda.backes@gmail.com, https://lattes.cnpq.br/I50I573I93830736

ISSN 2448-0479 Submetido em: 3I ago. 2020. Aceito: 08 jan. 202 I.

DOI: http://dx.doi.org/I0.21674/2448-0479.7I.4I-49

\section{Resumo}

O paisagismo tem como finalidade ornamentar ambientes, utilizando espécies vegetais com aptidões multifuncionais, como as plantas bioativas, além de considerar, também, uma forma de preservação do patrimônio vegetal. As plantas bioativas são aquelas que apresentam princípios ativos que possibilitam diversos benefícios aos seres vivos, desde comestível, medicinal a ornamental. Assim, o presente trabalho teve como objetivo realizar uma revisão de literatura sobre o uso de plantas bioativas no paisagismo. A metodologia adotada foi por meio de pesquisa bibliográfica em livros, artigos e plataformas digitais. Observou-se que há um grande número de espécies vegetais (arbóreas, arbustivas e de forração) que podem ser caracterizadas como bioativas, sendo a essas atribuídas um ou mais usos quanto a sua finalidade, seja alimentar, medicinal, condimentar, aromática, fitorremediadora de ambientes contaminados, fungicida e inseticida natural, entre outros. Conclui-se que o uso destas plantas em áreas ajardinadas, com paisagismo, proporcionam aos seus usuários uma multifuncionalidade, quer seja pelo embelezamento destes ambientes, como pelos aspectos psicológicos e ecológicos, ao mesmo tempo que resgata valores culturais e ideológicos, preserva a flora desses ambientes.

Palavras-chave: Ajardinamento. Bioatividade vegetal. Plantas de múltiplos propósitos.

\section{Abstract}

\section{Bioactive plants for use in landscaping}

The landscaping purpose is to decorate environments, using plant species with multifunctional aptitudes, such as bioactive plants, in addition to considering, also, a way of preserving plant heritage. Bioactive plants have active ingredients providing several benefits to living beings, from edible, medicinal to ornamental. Therefore, the present study aimed to conduct a literature review on the use of bioactive plants in landscaping. The methodology adopted was through bibliographic research in books, articles and digital platforms. It was remarked that a vast array of plant species (tree, shrub and forage) can be characterized as bioactive, with one or more uses attributed to their purpose, being food, medicinal, spice, aromatic, plants phytoremediation, contaminated environments, fungicide and natural insecticide, among others. It is concluded that the use of these plants in landscaped areas, with landscaping, provide their users with a multifunctionality, either for the beautification of these environments, as for the psychological and ecological aspects, at the same time that it rescues cultural and ideological values, preserves the flora of these environments.

Keywords: Landscaping. Plant bioactivity. Multi-purpose plants. 


\section{Resumen}

\section{Plantas bioactivas para uso en el paisajismo}

El paisajismo tiene como finalidad decorar ambientes, utilizando especies vegetales con habilidades multifuncionales, como las plantas bioactivas, además de considerar, también, una forma de preservar el patrimonio vegetal. Las plantas bioactivas son aquellas que poseen principios activos que brindan diversos beneficios a los seres vivos, desde comestibles, medicinales hasta ornamentales. Así, el presente trabajo tuvo como objetivo realizar una revisión de la literatura sobre el uso de plantas bioactivas en el paisajismo. La metodología adoptada fue a través de la investigación bibliográfica en libros, artículos y plataformas digitales. Se observó que existe una gran cantidad de especies vegetales (arbóreas, arbustivas y forrajeras) que se pueden caracterizar como bioactivas, con uno o más usos atribuidos a su finalidad, ya sea alimenticia, medicinal, especiada, aromática, fitorremediación, ambientes contaminados, fungicida e insecticida natural, entre otros. Se concluye que el uso de estas plantas en áreas ajardinadas, con paisajismo, proporcionan a sus usuarios una multifuncionalidad, tanto por el embellecimiento de estos ambientes, como por los aspectos psicológicos y ecológicos, a la vez que rescata valores culturales e ideológicos, preserva la flora de estos ambientes.

Palabras clave: Paisajismo. Bioactividad vegetal. Plantas multiusos.

\section{Introdução}

A paisagem dentro de um contexto contemporâneo passa a ser avaliada como uma interação de fatores envolvendo os valores ecológicos, funcionais e socioambientais que contribuem para a melhor qualidade de vida das pessoas. O paisagismo e diferentes espaços de ocupação urbana é uma percepção de melhoria no ambiente e na paisagem, influenciando o comportamento individual ou em grupo (MENEGAES et al., 2020).

A distribuição da vegetação na paisagem urbana (jardins, parques, praças, espaços sociais, áreas verdes, entre outros) depende do modelo de crescimento do local, que é resultado das características culturais e das peculiaridades ambientais deste local, no tempo (MARX; TABACOW, 2004; NIEMEYER, 2005; LEAL; BIONDI, 2006). Ou seja, o paisagismo é o resultado da escolha e das aspirações de uma sociedade que engloba a sua cultura, economia e política em um período temporal.

A sobrevivência da vegetação no meio urbano se dá pela disputa por espaços públicos entre as diferentes atividades e o ajardinamento. Em paisagismo, a necessidade de um planejamento com a escolha adequada das plantas, como ponto fundamental para a minimização dos conflitos gerados entre as ocupações dos espaços, sejam eles edificados ou ajardinados torna-se fundamental (ABBUD, 2006; GONÇALVES; PAIVA, 2006; TUAN, 20 I2), onde as plantas são elementos vivos imprescindíveis na transformação de ambientes áridos em espaços de convivência que trazem melhor qualidade de vida para as pessoas.

Um ambiente com paisagismo harmônico com o seu entorno, ao mesmo tempo em que se espelha na cultura, deve constituir-se de elementos de valorização proporcionando aos seus usuários um espaço de convivência e contemplação. A implantação da vegetação deve atingir os objetivos de ornamentação, proporcionando melhoria no microclima e diminuição da poluição, sendo essa fundamentada em critérios técnico-científicos que viabilizam tais funções, bem como o bem-estar (CAVALCANTI et al., 2003; ALENCAR; CARDOSO, 20I5; MENEGAES et al., 2016).

O paisagismo funcional utiliza plantas com múltiplos propósitos, como as plantas bioativas, que proporcionam benefícios relacionados à alimentação e à medicina popular, entre outros, podendo também ser empregado para embelezamento estético do ambiente. O conhecimento da multifuncionalidade de plantas, especialmente as bioativas, possibilita e estimula a comunidade na preservação dos espaços sociais e de áreas verdes de interesse e de convívio. Ambientes revitalizados por meio do paisagismo permitem ao contemplador (observador) um resgate dos valores culturais e ideológicos, especialmente, em espaços onde a natureza está inserida no seu cotidiano (BACKES, 20I 2; LAWS, 20I3; MENEGAES et al., 20I6; MARODIN; SOUZA, 20I6).

As plantas bioativas têm relação direta com a biodiversidade local, atribuindo uma herança cultural de preservação do patrimônio vegetal, solo, água e das peculiaridades do agroecossistema (LOPES; LINK, 20I I). Há necessidade de saber utilizar os benefícios dos vegetais tanto para a alimentação, proteção, fortalecimento 
e desintoxicação do nosso organismo e do meio ambiente, como para a ornamentação dos espaços de convívio comum (BACKES, 20I3).

Neste contexto, o potencial ornamental de plantas bioativas para uso no paisagismo de espaços sociais e áreas verdes, torna-se importante para propiciar uma harmonização da utilização destas plantas no paisagismo funcional. Independente da sua finalidade bioativa, o emprego destas plantas no paisagismo embeleza e mantém o patrimônio vegetal da região (biodiversidade). Assim, o presente trabalho teve como objetivo realizar uma revisão de literatura sobre o uso de plantas bioativas no paisagismo.

\section{Material e Métodos}

Para a elaboração do presente trabalho realizou-se uma revisão de literatura baseada em artigos científicos e livros, todos referente a temática abordada conforme sugerido por Pereira et al. (20l8). Para a obtenção das referências citadas neste trabalho foram consultadas na biblioteca do Centro de Ciências Rurais da Universidade Federal de Santa Maria e nos endereços eletrônicos de pesquisa, como, SciELO, Google Acadêmico e Portal de Periódicos CAPES (Coordenação de Aperfeiçoamento de Pessoal de Nível Superior).

Utilizando seguintes palavras-chave para essa pesquisa: "espaços ajardinados", "plantas com bioatividade", "plantas bioativas vegetal", "plantas com múltiplos propósitos" e "paisagismo funcional”. Após analisadas as referências contendo as palavras-chave, selecionou-se as que contemplavam a temática norteadora deste trabalho.

\section{Paisagismo}

O paisagismo como ferramenta multidisciplinar engloba a ciência e a arte de forma indissociável e, quando ordenado de forma harmônica resulta em uma paisagem aprazível, e grande deleito pelo homem. Como ciência o paisagismo lança mão do ecletismo que envolve as distintas áreas do conhecimento como: botânica, biologia e ecofisiologia vegetal, fitotecnia, matemática, física, engenharias de água, solo e edificações, agroclimatologia, fitogeografia, entre outros, possibilitando classificar as espécies com diferentes potenciais e aptidão de uso. Enquanto arte, mescla a plasticidade das plantas à sua estética, pela diversidade de portes, formas, estruturas, cores, texturas, entre outras, atribuindo valor artístico ao ambiente (LIRA FILHO; PAIVA; GONÇALVES, 200I; PETRY, 20I4; FARIA; ASSIS; COLOMBO, 20I8; MENEGAES, 2020).

O paisagismo proporciona à comunidade usar ampla e irrestritamente seus benefícios, socializando o ambiente de convívio, quer seja um espaço público ou privado. O diagnóstico das características estéticas da paisagem deve ser o ponto de partida para a seleção das plantas a serem utilizadas nestes espaços, respeitando os saberes e valores culturais e afetivos desta comunidade (NIEMEYER, 2005; BACKES, 20I2; ALENCAR; CARDOSO, 20I5).

Fazer a identificação de representações iconográficas de paisagens e das espécies vegetais aptas para a ornamentação é de suma importância. O conhecimento popular é influenciado pelo repertório cultural de cada comunidade, as quais desenvolveram à sua maneira diferentes formas de explorar as heterogeneidades dos ambientes adaptando-se e escolhendo as plantas que mais apreciam, quer seja de caráter estético (ornamental) ou alimentar (PINTO et al., 2006; LOPES; LINK, 20I I; LAWS, 20I3). A menção do trabalho do paisagista brasileiro de maior renome mundial Roberto Burle Marx, que insistia e investia em seus projetos paisagísticos a criação de medidas necessárias para que a população pudesse valorizar e reconhecer a flora local (MARX; TABACOW, 2004; ALVES; PAIVA, 2008).

O uso e o cultivo de plantas com finalidade ornamental ocorrem desde as primeiras civilizações, pois estas perceberam características peculiares, alimentares e medicinais, e estéticas que apreciavam (HEIDEN et al., 2006). Inicialmente, o uso de plantas ornamentais foi organizado na forma de horto ou jardins utilitários (plantas comestíveis, condimentares, aromáticas, medicinais, pomares, entre outros) fazendo menção ao "paraíso na Terra" (ALVES; PAIVA, 2008; FARIA; ASSIS; COLOMBO, 20I8). Sendo neste caso o paisagismo responsável pela promoção de conforto e convívio social, resultante da interação das plantas-pessoas-espaços em um espaço funcional. Menegaes e colaboradores (2016) apontam a necessidade de se realizar estudos técnicos e científicos específicos para proporcionar conforto e convívio em diferentes espaços sociais e áreas verdes.

$\mathrm{Na}$ atualidade, o jardim ampliou suas funções e tornou-se muito mais que um lugar de contemplação como os antigos quintais. $O$ jardim passou a ser utilizado para encontros prazerosos entre amigos e familiares, 
além de ambiente para a leitura, meditação e relaxamento (ABBUD, 2006; FARIA; ASSIS; COLOMBO, 20I8). Em concordância com os autores supracitados, o jardim também oferece sensações como o perfume das flores, o canto dos pássaros, o frescor da brisa e até o simples ato de saborear as frutas diretamente do pé.

\section{Plantas Bioativas}

Neste sentido, o potencial ornamental de plantas bioativas para uso no paisagismo de espaços sociais, áreas verdes, telhados vivos, paredes verdes, jardins sensoriais, paisagismo funcional, escolar e regenerativo, entre outros, indica uma amplitude e variabilidade no uso desse grupo de plantas nos diversos ambientes, resgatando a identidade local, ao mesmo tempo em que preserva a biodiversidade regional (fitogeográfica). Backes (2013) aponta a importância de se conhecer a aptidão de uso das espécies vegetais para a criação de uma paisagem útil, funcional e inclusiva, como ocorre no paisagismo bioclimático (peles, cortinas, paredes, tetos e telhados verdes) e regenerativo (espaços naturais e antrópicos).

Petry (20I4) e Bevilaqua e colaboradores (2015) destacam que é essencial conhecer com propriedade as espécies vegetais selecionadas para a utilização em espaços ajardinados, especialmente os escolares, em virtude de algumas plantas apresentarem toxicidade aos humanos, bem como aos animais. O Sistema Nacional de Informação Tóxico-Farmacológicas (Sinitox) lista e solicita não utilizar no paisagismo espécies de caráter ornamentais já popularizadas, por exemplo, copo-de-leite (Zantedeshia aethiopica Spreng), coroa-de-cristo (Euphobia milli L.), comigo-ninguém-pode (Dieffenbachia picta Schott), espirradeira (Nerium oleander L.), cinamomo (Melia azedarach L.), entre outras, em virtude da sua toxicidade comprovada.

A terminologia para plantas bioativas está diretamente relacionada às espécies vegetais de cunho medicinal, pois nos últimos anos houve um grande resgate de uso de plantas com esse objetivo. Contudo, bioatividade das plantas engloba todas que apresentem caráter funcional seja alimentar (grãos, frutíferas, folhosas, raízes, entre outros), medicinal, condimentar, aromática, fitorremediadora de ambientes contaminados, fungicida e inseticida natural, entre outros (Figura I). Muitas plantas alimentícias de cunho bioativo, atualmente, são classificadas como plantas alimentícias não convencionais (PANC) devido a sua amplitude de usos (CLEMENTE; HABER; 20I3; KINUPP; LORENZI, 20I4). Ou seja, as plantas bioativas são espécies vegetais que proporcionam ao usuário um benefício por meio de um ou mais princípios ativos, conhecidos como fitocomplexo, que é o conjunto de todas as substâncias presentes na planta (vitaminas, sais minerais, resinas, entre outras), e que agem melhorando o efeito desejado ou preconizado (STASI, 1996; LOPES; LINK, 20I I; BEVILAQUA et al., 20I5; MARODIN; SOUZA, 2016).

Clemente e Haber (2013) e Bevilaqua e colaboradores (20I5) apontam para a necessidade de classificar as espécies bioativas devido à grande semelhança morfológica de suas folhas, flores, frutos e raízes, para distinguir sua funcionalidade e toxicidade. Muitas delas podem ser utilizadas, também, para a ornamentação, em virtude de suas características estéticas e plásticas. Vários autores vêm trabalhando com a temática de classificar o potencial ornamental de diferentes espécies vegetais nativas ou não de uma região (CHAMAS; MATTHES, 2000; GUARIM NETO; MORAIS, 2003; HEIDEN et al., 2006; LEAL; BIONDI, 2006; STUMPF et al., 2009).

Figura I - Múltiplos usos das plantas bioativas.

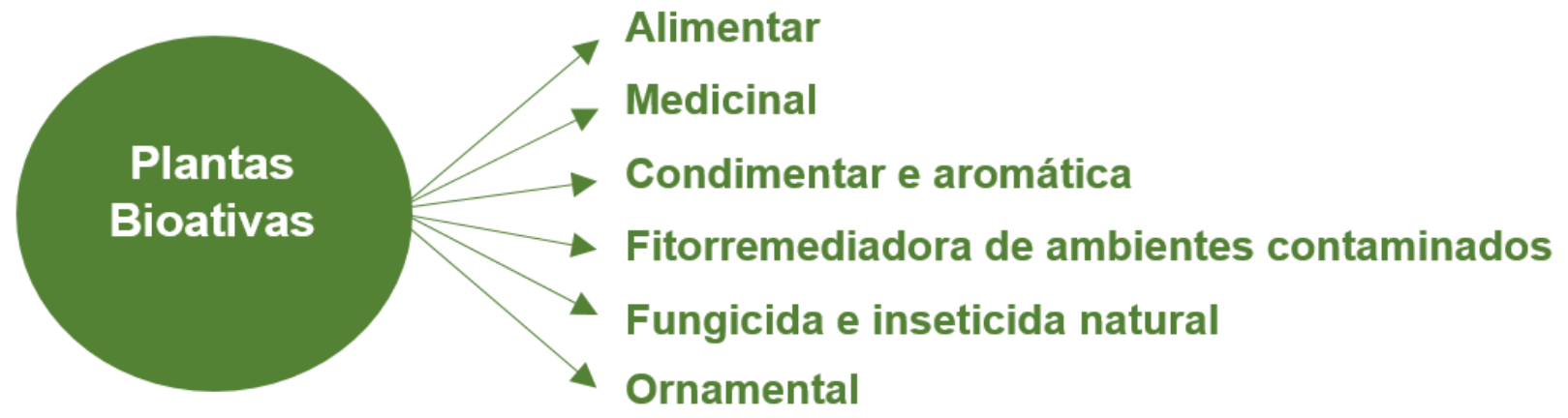

Fonte: Autoras (2020). 
Por exemplo, Clemente e Haber (2013) e Kinupp e Lorenzi (2014) indicam algumas plantas bioativas já conhecidas pelas suas características ornamentais e utilizadas no paisagismo como: alecrim (Rosmarnus officinalis L.) com finalidades condimentar, aromática, medicinal e cosmética; calêndula (Calendula officinalis L.) muito utilizada pela Cruz-Vermelha para cataplasma para doenças de pele e na forma de chá; camomila (Chanomila recutita L.) com finalidades medicinal, alimentícia e cosmética (produtos capilares); capuchinha (Tropaeolum majus L.) com finalidade alimentícia quanto às flores e frutos, rica em vitamina C; gerânio (Pelargonium graveolens L.) utilizado na perfumaria devido seu excelente óleo essencial; e violeta-chinesa (Asystasia gangetica L.) com finalidade alimentícia quanto às flores e folhagem, rica em ferro, entre outras.

\section{Classificação quanto ao uso das plantas bioativas}

As plantas bioativas podem ser classificadas da seguinte forma:

- Alimentícias são aquelas que possuem uma ou mais partes que podem ser consumidas cruas ou após processada ou cozida, como: sementes, brotos, folhas, flores, grãos, raízes, entre outros (KINUPP; LORENZI, 20I4).

- Medicinais são aquelas cujo emprego é destinado à recuperação da saúde e bem-estar humano ou animal. A sua aplicabilidade dever ser realizada por um profissional da saúde com base nos conceitos da Organização Mundial da Saúde (OMS) (LORENZI; MATOS, 2008).

- Condimentares são aquelas utilizadas para conservar e/ou realçar o sabor de alimentos e bebidas (CLEMENTE; HABER, 20I3; KINUPP; LORENZI, 20I4).

- Aromáticas são aqueles que conferem aroma ou fragrância quando acrescidas em alimentos, bebidas, chás, infusões ou cosméticos (CLEMENTE; HABER, 20I3; KINUPP; LORENZI, 20I4).

- Fitorremediadoras de ambientes contaminados são aquelas espécies que têm a capacidade de absorver elementos contaminantes presentes no solo ou na água armazenando, transportando e/ou acumulando-os na sua parte subterrânea ou aérea (MELO; MENEGAES; MELO, 2020).

- Fungicidas e inseticidas naturais são aquelas plantas que apresentam substâncias repelentes a fungos ou a insetos, seja na forma sistêmica ou por contato, fazendo seu controle ou impedindo seu ataque a outras plantas (PENTEADO, 2007).

- Tóxicas são plantas que causam ou apresentam algum efeito tóxico ao serem manuseadas ou ingeridas (BEVILAQUA et al., 20I5).

- Ornamentais são aquelas espécies botânicas que se distinguem pelo intenso e exuberante florescimento e cor da folhagem, forma, textura e arquitetura da planta, visando preencher espaços para deleite do ser humano (KÄMPF, 2000; LORENZI, 20I3).

De acordo, com o preconizado por Lopes e Link (20I I), em que as plantas bioativas também podem auxiliar na preservação da biodiversidade local, resgatando os conceitos iniciais do paisagismo com uso espécies ornamentais de múltiplos propósitos. No Quadro I, foram eleitas algumas espécies com caráter ornamental para uso no paisagismo e outros fins.

Quadro I - Algumas plantas bioativas de caráter ornamental para uso no paisagismo.

\begin{tabular}{|c|c|c|c|}
\hline $\begin{array}{l}\text { Uso no } \\
\text { paisagismo }\end{array}$ & $\begin{array}{l}\text { Nome popular } \\
\text { (Nome científico) }\end{array}$ & $\begin{array}{l}\text { Característica } \\
\text { ornamental }\end{array}$ & Outros usos \\
\hline Árvore & $\begin{array}{c}\text { Erva-mate } \\
\text { (Ilex paraguariensis A. St.-Hil.) }\end{array}$ & Intensa folhagem & $\begin{array}{l}\text { Alimentar: folhas secas } \\
\text { Medicinal: folhas secas }\end{array}$ \\
\hline Árvore & $\begin{array}{c}\text { Ipê-amarelo } \\
\text { (Handroanthus chysotrchus (Mart. ex DC.) Mattos) }\end{array}$ & $\begin{array}{l}\text { Intenso florescimento } \\
\text { de cor amarela }\end{array}$ & $\begin{array}{l}\text { Alimentar: flores cozidas; } \\
\text { Melífera: flores }\end{array}$ \\
\hline Árvore & $\begin{array}{l}\text { Limoeiro } \\
\text { (Citrus limon (L.) Burm.f.) }\end{array}$ & $\begin{array}{l}\text { Intensa folhagem e } \\
\text { frutificação }\end{array}$ & $\begin{array}{l}\text { Alimentar: frutos; } \\
\text { Medicinal: folhas e frutos }\end{array}$ \\
\hline Árvore & $\begin{array}{c}\text { Pata-de-vaca } \\
\text { (Bauhinia cheilantha (Bong.) Steud) }\end{array}$ & $\begin{array}{l}\text { Intensa folhagem } \\
\text { com florescimento na } \\
\text { coloração branco }\end{array}$ & Medicinal: folhas \\
\hline Árvore & $\begin{array}{c}\text { Pitangueira } \\
\text { (Eugenia uniflora L.) }\end{array}$ & $\begin{array}{l}\text { Intensa folhagem e } \\
\text { frutificação }\end{array}$ & $\begin{array}{l}\text { Alimentar: frutos; } \\
\text { Medicinal: folhas e frutos }\end{array}$ \\
\hline
\end{tabular}




\begin{tabular}{|c|c|c|c|}
\hline $\begin{array}{c}\text { Uso no } \\
\text { paisagismo }\end{array}$ & $\begin{array}{l}\text { Nome popular } \\
\text { (Nome científico) }\end{array}$ & $\begin{array}{l}\text { Característica } \\
\text { ornamental }\end{array}$ & Outros usos \\
\hline Arbusto & $\begin{array}{l}\text { Alecrim } \\
\text { (Rosmarinus officinalis L.) }\end{array}$ & $\begin{array}{l}\text { Intensa folhagem de } \\
\text { textura fina }\end{array}$ & $\begin{array}{c}\text { Aromática: folhas; } \\
\text { Condimentar: folhas e flores; } \\
\text { Medicinal: folhas }\end{array}$ \\
\hline Arbusto & $\begin{array}{l}\text { Flor-de-cardeal } \\
\text { (Ipomoea quamoclit L.) }\end{array}$ & $\begin{array}{l}\text { Intensa folhagem e } \\
\text { florescimento na cor } \\
\text { vermelho }\end{array}$ & $\begin{array}{l}\text { Alimentar: folhas e flores; } \\
\text { Medicinal: folhas e flores }\end{array}$ \\
\hline Arbusto & $\begin{array}{c}\text { Lantana } \\
\text { (Lantana camara L.) }\end{array}$ & $\begin{array}{c}\text { Intensa folhagem e } \\
\text { florescimento nas cores } \\
\text { amarelo, laranja e } \\
\text { vermelho }\end{array}$ & $\begin{array}{l}\text { Medicinal: folhas e flores } \\
\text { Tóxica: para bovinos e ovinos }\end{array}$ \\
\hline Arbusto & $\begin{array}{c}\text { Manacá } \\
\text { (Brusenfelsia uniflora (Pohl) D. Don) }\end{array}$ & $\begin{array}{l}\text { Intensa folhagem } \\
\text { e florescimento na } \\
\text { coloração branco e } \\
\text { tons de lilás }\end{array}$ & $\begin{array}{l}\text { Aromática: folhas; } \\
\text { Medicinal: folhas }\end{array}$ \\
\hline Arbusto & $\begin{array}{c}\text { Vinagreira } \\
\text { (Hibiscus acetosella Welw. ex Hiern) }\end{array}$ & $\begin{array}{l}\text { Intensa folhagem na } \\
\text { coloração arroxeada e } \\
\text { flores róseas }\end{array}$ & $\begin{array}{l}\text { Alimentar: folhas e frutos; } \\
\text { Medicinal: folhas, flores e } \\
\text { frutos }\end{array}$ \\
\hline $\begin{array}{l}\text { Forração } \\
\text { perene }\end{array}$ & $\begin{array}{c}\text { Alternantera } \\
\text { (Alternanthera brasiliana (L.) Kuntze) }\end{array}$ & $\begin{array}{l}\text { Folhagem na coloração } \\
\text { arroxeada }\end{array}$ & Medicinal: folhas e flores \\
\hline $\begin{array}{l}\text { Forração } \\
\text { perene }\end{array}$ & $\begin{array}{l}\text { Capuchinha ou nastúrcio } \\
\text { (Tropaeolum majus L.) }\end{array}$ & $\begin{array}{c}\text { Intensa folhagem e } \\
\text { florescimento nas cores } \\
\text { amarelo, laranja e } \\
\text { vermelho }\end{array}$ & $\begin{array}{l}\text { Alimentar: folhas, flores e } \\
\text { frutos; } \\
\text { Medicinal: folhas e flores }\end{array}$ \\
\hline $\begin{array}{l}\text { Forração } \\
\text { perene }\end{array}$ & $\begin{array}{c}\text { Capim-limão } \\
\text { (Cymbopogon citratus (DC.) Stapf) }\end{array}$ & Intensa folhagem & $\begin{array}{l}\text { Aromática: folhas; } \\
\text { Fungicida e inseticida: folhas }\end{array}$ \\
\hline $\begin{array}{l}\text { Forração } \\
\text { perene }\end{array}$ & $\begin{array}{c}\text { Echinacea } \\
\text { (Echinacea purpurea (L.) Moench) }\end{array}$ & $\begin{array}{l}\text { Intensa folhagem } \\
\text { e florescimento na } \\
\text { coloração rósea }\end{array}$ & Medicinal: folhas e flores \\
\hline $\begin{array}{l}\text { Forração } \\
\text { perene }\end{array}$ & $\begin{array}{c}\text { Folha-da-fortuna } \\
\text { (Kalanchoe pinnata (Lam.) Pers.) }\end{array}$ & $\begin{array}{l}\text { Intensa folhagem de } \\
\text { aspecto suculento }\end{array}$ & $\begin{array}{l}\text { Alimentar: folhas; } \\
\text { Medicinal: folhas }\end{array}$ \\
\hline $\begin{array}{l}\text { Forração } \\
\text { perene }\end{array}$ & $\begin{array}{c}\text { Gerânio } \\
\text { (Pelargonium domesticum L.H. Bailey) }\end{array}$ & $\begin{array}{c}\text { Intensa folhagem e } \\
\text { florescimento nas cores } \\
\text { branca, lilás e vermelha }\end{array}$ & $\begin{array}{l}\text { Aromática: folhas; } \\
\text { Medicinal: folhas }\end{array}$ \\
\hline $\begin{array}{l}\text { Forração } \\
\text { perene }\end{array}$ & $\begin{array}{l}\text { Lavanda } \\
\text { (Lavandila dentada L. e L. angustifolia Mill.) }\end{array}$ & $\begin{array}{l}\text { Intensa folhagem } \\
\text { e florescimento na } \\
\text { coloração lilás }\end{array}$ & $\begin{array}{l}\text { Aromática: folhas e flores; } \\
\text { Medicinal: folhas e flores }\end{array}$ \\
\hline $\begin{array}{l}\text { Forração } \\
\text { perene }\end{array}$ & $\begin{array}{c}\text { Manjericão } \\
\text { (Ocimum basilicum L.) }\end{array}$ & Intensa folhagem & $\begin{array}{l}\text { Aromática: folhas; } \\
\text { Condimentar: folhas e flores; } \\
\text { Medicinal: folhas } \\
\text { Melífera: flores }\end{array}$ \\
\hline $\begin{array}{l}\text { Forração } \\
\text { perene }\end{array}$ & $\begin{array}{c}\text { Pervinca } \\
\text { (Catharanthus roseus (L.) G. Don) }\end{array}$ & $\begin{array}{c}\text { Intenso florescimento } \\
\text { nas cores branco a } \\
\text { rósea }\end{array}$ & Medicinal: folhas e flores \\
\hline $\begin{array}{l}\text { Forração } \\
\text { perene }\end{array}$ & $\begin{array}{c}\text { Sabão-de-jardim } \\
\text { (Saponaria officinalis L.) }\end{array}$ & $\begin{array}{l}\text { Intenso florescimento } \\
\text { na coloração rósea }\end{array}$ & $\begin{array}{l}\text { Aromática: para uso e sabões; } \\
\text { Medicinal: hastes e rizomas }\end{array}$ \\
\hline Forração anual & $\begin{array}{c}\text { Amor-perfeito } \\
\text { (Viola } \times \text { wittrockiana Gams) }\end{array}$ & $\begin{array}{l}\text { Intenso florescimento } \\
\text { nas cores variadas }\end{array}$ & Alimentar: flores \\
\hline Forração anual & $\begin{array}{c}\text { Begônia } \\
\text { (Begonia } x \text { hydrida Hort. var. Dragon wing) }\end{array}$ & $\begin{array}{l}\text { Intenso florescimento } \\
\text { na cor vermelho }\end{array}$ & Alimentar: flores \\
\hline Forração anual & $\begin{array}{c}\text { Calêndula } \\
\text { (Calendula officinalis L.) }\end{array}$ & $\begin{array}{l}\text { Intenso florescimento } \\
\text { nas cores amarelo e } \\
\text { laranja }\end{array}$ & $\begin{array}{l}\text { Alimentar: folhas e flores; } \\
\text { Medicinal: folhas e flores }\end{array}$ \\
\hline Forração anual & $\begin{array}{c}\text { Celosia } \\
\text { (Celosia argentea L.) }\end{array}$ & $\begin{array}{l}\text { Intenso florescimento } \\
\text { na cor vermelho }\end{array}$ & $\begin{array}{l}\text { Alimentar: folhas e sementes } \\
\text { Indicadora: para nematoides }\end{array}$ \\
\hline
\end{tabular}




\begin{tabular}{lccc}
\hline $\begin{array}{c}\text { Uso no } \\
\text { paisagismo }\end{array}$ & $\begin{array}{c}\text { Nome popular } \\
\text { (Nome científico) }\end{array}$ & $\begin{array}{c}\text { Característica } \\
\text { ornamental }\end{array}$ & Outros usos \\
\hline Forração anual & $\begin{array}{c}\text { Cravina } \\
\text { (Dianthus chinensis L.) }\end{array}$ & $\begin{array}{c}\text { Intenso florescimento } \\
\text { nas cores branco a } \\
\text { róseos }\end{array}$ & $\begin{array}{c}\text { Alimentar: flores; } \\
\text { Fitorremediadora: solo }\end{array}$ \\
Forração anual & $\begin{array}{c}\text { Tagetes } \\
\text { (Tagetes erecta L.) }\end{array}$ & $\begin{array}{c}\text { Intenso florescimento } \\
\text { nas cores amarelo e } \\
\text { laranja }\end{array}$ & $\begin{array}{c}\text { Aromática: folhas e flores; } \\
\text { Fungicida e inseticida: folhas } \\
\text { e flores }\end{array}$ \\
\hline
\end{tabular}

Fonte: adaptado de LORENZI; MATOS, 2008; CLEMENTE; HABER, 20I3; LORENZI, 20I3; KINUPP; LORENZI, 2014.

No Quadro I, elencou-se algumas as espécies botânicas com características ornamentais e bioativas para uso no paisagismo. Segundo Bellé (20I2), o paisagismo funcional (biativo) só é possível devido ao conhecimento das propriedades das espécies que o compõe, a fim de se obter o melhor aproveitado de seus benefícios no jardim. Para Alencar e Cardoso (2015), o paisagismo funcional permite decorar e ornamentar os ambientes naturais e construídos com o uso de plantas de múltiplos propósitos, considerando uma alternativa socioeconômica e sustentável, com enriquecimento em vários aspectos, especialmente a interação ecológica e social.

Em projetos paisagísticos a seleção da vegetação é uma das principais etapas, pela grande complexidade de informações botânicas, de crescimento e desenvolvimento dos vegetais, devendo ser avaliada pelo profissional a necessidade, o uso e a finalidade de cada espécie, além das condições ambientais do local a ser projetado. Para Backes (20I2) a escolha da vegetação a ser utilizada no paisagismo, deve contemplar todas as características de uma espécie, com um olhar planetário, em virtude da interação que ocorre entre as plantas para compor a paisagem.

Neste contexto, as plantas bioativas são espécies que devem ser inseridas pela extensa contribuição na melhoria da qualidade de vida que proporciona ao homem contemporâneo. Em ambiente escolar, estudos sobre educação ambiental buscam-se trabalhar com plantas por meio de horto escolar, sendo nesse caso muito importante a seleção correta das plantas a serem utilizadas. Alguns autores indicam sucesso na implantação de hortos escolares utilizando o paisagismo como ferramenta de estudo, como Saft et al. (20I I) na Escola Municipal de Ensino Fundamental Maria Ruth Raymundo em Sapiranga, RS, e Silva e Fogaça (2017) na Escola Estadual de Tempo Integral João dos Santos Braga em Manaus, AM.

\section{Considerações finais}

Os dados encontrados permitem identificar que o uso de plantas bioativas com potencial ornamental podem ser ajardinadas em espaços de convívio social, públicos, privados ou coletivos, além de áreas verdes, harmonizando esses ambientes com o cotidiano do paisagismo funcional, seja ele ornamental, alimentar, condimentar, medicinal ou de bem-estar. A seleção dessas plantas também pode auxiliar no resgate de valores culturais e ideológicos, especialmente, em ambientes ajardinados com espécies que proporcionem algum benefício seja físico, mental ou espiritual para as pessoas. Para caracterizar uma espécie como bioativa deve-se realizar um estudo minucioso de sua nomenclatura tanto popular como científica, diferenciando sua estrutura botânica com consulta a livros e materiais científicos desta área, a fim de confirmar seus benefícios de bioatividade.

Saber explorar o potencial ornamental, medicinal ou alimentar das espécies vegetais bioativas requer conhecimento teórico e prático, além de experiências vivenciadas pelo profissional no dia a dia com as plantas e conhecer o comportamento das mesmas para aplicar em projetos de paisagismo. A natureza, cada vez mais, está sendo requisitada para fazer parte da vida das pessoas e a utilização de plantas bioativas é uma oportunidade de o homem e a sociedade se relacionarem e se aproximarem desse vasto e rico grupo de espécies vegetais. 


\section{Referências}

ABBUD, B. Criando paisagens: guia de trabalho em arquitetura paisagística. $4^{\mathrm{a}}$ ed. São Paulo: SENAC, 2006. $20 \mathrm{Ip}$.

ALENCAR, L. D.; CARDOSO, J. C. Paisagismo funcional: o uso de projetos que integram mais que ornamentação. Revista Ciência, Tecnologia e Ambiente, São Carlos, v. I, n. I, p. I-7, 2015.

ALVES. S. F. S. N. C.; PAIVA, P. D. O. História e evolução dos jardins. In: PAIVA, P. D. O. Paisagismo - conceitos e aplicações. Lavras: UFLA, 2008. p. I2-65.

BACKES, M. A. T. Paisagismo para celebrar a vida - jardins como cura da paisagem e das pessoas. Porto Alegre: Paisagem do Sul, 2012. 163p.

BACKES, M. A. T. Paisagismo produtivo. Revista Brasileira de Horticultura Ornamental, Campinas, v. 19, n. I, p.4754, 2013.

BELILAQUA, G. A. P.; OLANDA, G. B.; SCHIDECK, G.; COUTO, M. E. O. Documentos 394 - Tecnologia de plantas medicinais e bioativas da flora de clima temperado. Pelotas: Embrapa Clima Temperado, 2015. 98 p.

BELLÉ, S. Plantas medicinais: caracterização, cultivo e uso paisagístico na Serra Gaúcha. Bento Gonçalves: IFRS Bento Gonçalves, 2012. 200p.

CAVALCANTI, M. L. F.; DANTAS, I. C.; LIRA, R. S.; OLIVEIRA, J. M. C.; ALBUQUERQUE, H. N.; ALBUQUERQUE, I. C. S. Identificação dos vegetais tóxicos da cidade de Campina Grande - PB. Revista de Biologia e Ciências da Terra, v.3, n.I, 2003.

CHAMAS, C. C.; MATTHES, L. A. F. Método para levantamento de espécies nativas com potencial ornamental. Revista Brasileira de Horticultura Ornamental, Campinas, v.6, n.2, p. 53-63, 2000.

CLEMENTE, F. M. V. T.; HABER, L. L. Plantas aromáticas e condimentares: usos aplicados na horticultura. Brasília: EMBRPA, 2013. 150p.

FARIA, R. T.; ASSIS, A. M.; COLOMBO, R. C. Paisagismo: Harmonia, Ciência e Arte. Londrina: Mecenas, 2018. I4Ip. GONÇALVES, W.; PAIVA, H. N. Silvicultura Urbana: implantação e manejo. Viçosa: Aprenda Fácil, 2006, 20 Ip.

GUARIM NETO, G.; MORAIS, R. G. Plantas medicinais com potencial ornamental: um estudo no cerrado de Mato Grosso. Revista Brasileira de Horticultura Ornamental, Campinas, v.9, n. I, p.89-97, 2003.

HEIDEN, G.; BARBIERI, R. L.; STUMPF, E. R. T. Considerações sobre o uso de plantas ornamentais nativas. Revista Brasileira de Horticultura Ornamental, Campinas, v. I2, nI, p.2-7, 2006.

KÄMPF, A. N. Produção comercial de plantas ornamentais. Guaíba: Agropecuária, 2000. 254 p.

KINUPP, V. F.; LORENZI, H. Plantas alimentícias não convencionais (PANC) no Brasil: guia de identificação, aspectos nutricionais e receitais ilustradas. Nova Odessa: Instituto Plantarum, 2014. 768p.

LAWS, B. 50 plantas que mudaram o rumo da história. Rio de Janeiro: Sextante, 2013. 224 p.

LEAL, L.; BIONDI, D. Potencial ornamental de espécies nativas. Revista Científica Eletrônica de Engenharia Florestal, Garça, v. 4, n. 8, p.I-16, 2006.

LIRA FILHO, J. A.; PAIVA, H. N.; GONÇALVES, W. Paisagismo - princípios básicos. Viçosa: Aprenda Fácil, 200I. I63p.

LOPES, J. M. D. C.; LINK, D. Implantação de um horto didático de plantas bioativas no município de Tupanciretã. Revista Eletrônica em Gestão, Educação e Tecnologia Ambiental, Santa Maria, v.2, n.2, p.225-250, 201 I. 
LORENZI, H. Plantas para o jardim no Brasil. Nova Odessa: Instituto Plantarum, 20I3. I088p.

LORENZI, H.; MATOS, F. J. A. Plantas medicinais no Brasil: nativas e exóticas. Nova Odessa: Instituto Plantarum, 2008. 554p.

MARODIN, G. A. B.; SOUZA, P.V. D. Pomar doméstico: planejamento, formação e tratos culturais. Porto Alegre: Dom Quixote, 2016.236 p.

MARX, R. B; TABACOW, J. Arte \& Paisagem. 2. ed. São Paulo: Studio Nobel, 2004. 22 Ip.

MELO, E. F. R.Q.; MENEGAES, J. F; MELO, R. H. R.Q. Green Chemistry for Sustainable Production and Consumption Patterns. In: LEAL FILHO, W.; AZUL, A.; BRANDLI, L.; ÖZUYAR, P.; WALL, T. (Eds). Responsible Consumption and Production. Encyclopedia of the UN Sustainable Development Goals. New York: Springer, Cham. 2020. G I-I4p.

MENEGAES, J. F. Educação Ambiental por meio de práticas de ajardinamento em espaços de convivência social em comunidades rurais. 2020. 65f. Monografia (Especialização em Educação Ambiental). Universidade Federal de Santa Maria, 2020.

MENEGAES, J. F.; BACKES, F. A. A. L.; ROCHA, K. M.; BALZAN, K. M. Práticas de paisagismo em espaços de convivência social em comunidades rurais e em centro de educação ambiental. Revista Monografias Ambientais, Santa Maria, v. I5, n.I, p.38I-392, 2016.

MENEGAES, J. F;; NISHIJIMA, T.; BACKES, F. A. A. L.; BENETTI, C. C. Práticas de ajardinamento em espaços de convivência em comunidades rurais como instrumento de Educação Ambiental. Research, Society and Development, v. 9, n. II, p. I-19, 2020.

NIEMEYER, C. A. C. Paisagismo no planejamento arquitetônico. Uberlândia: EDUFU, 2005. I7Ip.

PENTAEDO, S. R. Controle alternativo de pragas e doenças com as caldas bordalesa, sulfocálcica e Viçosa. Campinas: Via Orgânica, 2007. I52 p.

PEREIRA, A. S., SHITSUKA, D. M., PARREIRA, F. J., SHITSUKA, R. Metodologia da pesquisa científica. Santa Maria: UFMS, 2018. $119 p$.

PETRY, C. Paisagens e paisagismo: do apreciar ao fazer e usufruir. Passo Fundo: UPF, 20I4. 125p.

PINTO, E. P. P.; AMOROZO, M. C. M.; FURLAN, A. Conhecimento popular sobre plantas medicinais em comunidades rurais de mata atlântica - Itacaré, BA, Brasil. Acta Botânica Brasileira, v. 20, n.4, p.75I-762, 2006.

SAFT, D. M.; PERES, P. E. C.; LINH, D.; NISHIJIMA, T. Paisagismo no pátio escolar: a arte como instrumento de sensibilização à educação ambiental. REMOA, v.2, n.2, p. 285 -296, 201 I .

SILVA, M. D.; FOGAÇA, T. K. Paisagismo com arte uma solução para o ambiente escolar em Manaus/AM, 2016. Caderno Meio Ambiente e Sustentabilidade, v. II, n.6, p.5-19, 2017.

STASI, L. C. Plantas medicinais: arte e ciência. Um guia de estudo interdisciplinar. São Paulo: UNESP, 1996.

STUMPF, E. R. T.; BARBIERI, R. L.; HEIDEN, G. Cores e formas no Bioma Pampa: plantas ornamentais nativas. Pelotas: Embrapa Clima Temperado, 2009. 276 p.

TUAN, Y. Topofilia: Um estudo da percepção, atitudes e valores do meio ambiente. Tradução: Lívia de Oliveira. Londrina: Eduel, 2012. 342p. 